\title{
The wisdom of environment facilities and its architecture
}

$$
\text { Xi Zhou }{ }^{1, a} \text {, Dexiang Deng }{ }^{2, b} \text {, Yue Zhao }{ }^{3, c}
$$

$1,{ }^{2}$ No.28 Xianning west road, School of Human Settlements and Civil Engineering, Xi'an Jiao Tong University, Beilin District, Xi'an, China

No.2, Chongwen Road, College of Media and Arts of Chongqing, University of Posts and Telecommunications, Nanan Distict, Chongqing, China

${ }^{3}$ No.2, Chongwen Road, College of Media and Arts of Chongqing, University of Posts and Telecommunications, Nanan Distict, Chongqing, China

\section{a}

Keywords: Intelligent Environment ; Basic Operation ; Intelligent Service ; The collaboration of software and hardware

Abstract: the development of information, digital, and artificial intelligence, the development idea of intelligent Earth formed and opened the era of wisdom city, smart cities generate intelligent environmental facilities, operating as the data carrier running for wisdom city and the residents' smart living facilities, its architecture should be collaboratively develop with smart city operations, intelligence services and software hardware matching.

A variety of issues implicit latent in the development of the city, including society, economy, resources and environment etc.., the dominate reason is that the whole city is not developing a system that can self-regulate and sustain development. Basing on the information age's big data, cloud computing and artificial intelligence, the construction of smart cities is becoming a proposition of globalization. The smart cities of developed countries have developed rapidly.

\section{Smart environment facilities}

\section{The intelligent environmental facilities that the smart cities generate}

In the information age, the information highway program in the United States promotes the construction of an information-based city, basing on it, the idea of "Digital Earth" developed and raised the urban construction to the digital urban stage, informatization and digitization continue to develop, and the idea of "Intelligent Earth" brings the city to its wisdom. With the development of the intelligent city, the initial theoretical exploration stage entered the construction practice stage. Wisdom city construction of all kinds of information and physical union facilities constitutes the new form and organic part of the urban environmental infrastructure, and the integration of 
traditional environmental facilities and functional integration is becoming more and more obvious, then, the intelligent level of environmental facilities has become one of the most important indexes in the detection of the wisdom of a city. The construction of intelligent environmental facilities has become an important link in the construction of smart cities.

The wisdom extent and management level of a city's environmental facilities, directly affect the city appearance, traffic safety, social security and public life of happiness index, also the index of a nation's civilization degree. The urban wise environmental facilities provide people with more convenient service function, information service, interactive experience, at the same time, as an important carrier and data acquisition channels of city intelligent facilities, it also collect lots of data for the calculation of city. In the process of building a smart city, based on the Internet of things, LBS location service data, cloud computing, big data, 3S (Geographic information systems, Global positioning systems, Remote sensing) technology architecture open sharing system framework, combined with multidimensional data such as population data, spatial data of the city, adding the technologies and ideas of smart cities to the decision-making of urban environmental facilities, integrating data from multiple dimensions, thus mining data content for the intelligent analysis and countermeasures, improving intelligence, science and technology, the convenience of environment facilities, so as to optimize the human life. The construction of intelligent environmental facilities added Multi-disciplinary and interdisciplinary frontier information network, science and technology as technology support to achieve the perception of the city's data collection, all-round multi-angle of city resources integration, the coordination of different departments of the city, as well as the management regulation of the whole city, and ultimately form a smart city with sustainable urban development.

\section{The development of intelligent environmental facilities}

In foreign countries, the European opened the practice model for the wisdom city in twenty-first Century. The European Union set out the priorities and started the action in 2007. The northern Europe has achieved smart city to reduce congestion and greenhouse gas emissions through the construction of the smart city; America used the IoT information technology to digitize and integrate urban resources, intelligently respond to urban needs, effectively save costs and reduce the consumption of resources; Spain focused on sensor project, such as the parking sensor, the smart bin sensor, made the smart city build a fully practical foundation, such as parking sensor, wisdom dustbin sensor, so that the wisdom city could obtained sufficient practice foundation; based on network technology, Korea tried to establish the digital and intelligent city, the "u-korea" strategy was launched in 2003 and the "smart Seoul 2015" strategy was launched in June 2011; the 
government of Singapore introduced the idea of "intelligent island" more than a decade ago,established the "e-government" to service citizens and provided more convenience for the citizens to handle government business; the Japanese government launched the "i-japan wisdom Japan strategy 2015" in July 2009, seized the initiative of smart grid technology, focused on the three major areas of personnel training, medical services and e-government. "In 1997, the world smart city BBS suggested that more than 50, 000 cities and regions would join the ranks of smart cities' construction in the future."

The smart cities' construction advanced by China is different from IBM's concept of smart cities, it's huge and systematic, not only information technology, it concerns many fields like social optimization, economic development, industrial layout, business operation and consumer behavior etc, with higher construction idea, it aims to regulate sustainable development through smart cities' construction. The rapid construction of smart cities in China is driving the development of intelligent and environmental facilities.However, the research and construction of intelligent environment facilities in China is still relatively backward compared with the United States, Europe, Japan and other countries, the road of intelligent environment facilities is long but the prospect is bright.

\section{The architecture of the intelligent environment facilities}

The construction and development of smart cities is mainly based on four aspects: intellectual foundation, intelligent management service, intellectual and economic humanity and comprehensive security of wisdom. Based on the development of the Internet, the Internet of things and cloud computing in the age of big data, smart city achieve the combination of the real world and the digital world through the integration and operation of data, so as to realize the intelligent monitoring, intelligent control and intelligent service for people and things, thus, coordinating the relationship between man and nature, achieving sustainable development, optimizing human life and making human life better on earth.

Based on the architecture of the smart city, as the subsystem of the smart city, the intelligent environment facilities' framework should be launched under the co-ordination of the intelligent city. Because of its complicated system and vast project, the structure of the two elements of government and market need to be coordinated. The government needs to summarize the particularity and unity according to the characteristics and functions of different cities, and carry out the implementation after the top-level design; the market should remain active and participate in the construction of the urban environmental infrastructure wisdom, increasing the competitiveness of intelligence environment facilities market with their own talent, technology, capital and other effective 
configuration elements.

In the framework of intelligent environmental facilities, the dominant role of the government can be divided into two kinds, one is the government invest in research and development construction actively, in this way, taking the government capital as the main body, from the development of the intelligent environmental facilities to the related intelligent environmental place, is dominated by the government, trying to make better service to the general public system of intelligent environmental facilities. The other is the tender development of the government, and promote the market enthusiasm, let the market develop the intelligent environmental facilities in a reasonable and effective competition environment, improving the design level of wisdom environmental facilities and research and development ability.

In addition to the hard conditions of the intellectual environmental facilities, the development of flexible conditions must be emphasized at the same time. Not only to meet the hardware conditions of wisdom city construction, the goal of enforcing intelligent environmental facilities is also to improve the safety and well-being of people in use and life and improve the quality of life for the masses, so the core of intelligent environmental facilities should be people-oriented, taking the intimate degree of human service as a standard for soft conditions, paying more attention to the emotional, interactive entertainment of people in research and development, making it the most basic function of the masses.

First of all, the intelligent basic operation is the root of the smart environmental facilities, and it's architecture should start from the infrastructure. Not to make individual or localised development, establishing an overall framework needs to proceed the development and construction unitedly and platformalizely. The overall basic operating mode will be technologically supported by the IoT, cloud computing and artificial intelligence etc, with a single environmental facility, cover all the environmental facilities in city to form a surface; through the characteristics of cloud computing, establishing a smart platform for urban environmental facilities, operating and maintaining the city's environmental facilities more efficiently by using the data collection and analysis of environmental facilities and the surroundings. This will not only reduce unnecessary waste of resources but also control the overall cost of the operation of environmental facilities.

Secondly, the service of intelligent environmental facilities is the essence. This service is various and collaborative, not a single service, meanwhile, this service is also intelligent, covering various sectors of the industry, such as urban services, environmental protection, urban transportation, urban construction, etc; aiming at providing great help to government and city enterprises. The government is familiar with every intelligent environment device and other detailed information through the IoT connects, making effective decisions for the management of city 
construction planning and rational utilization of energy by the calculation of the cloud computing platform and large data storage and data obtained; and companies can get to know the people's habits and some of the distribution of population density by some appropriate intelligence data in reasonable way, it can help companies do better market research. Based on these services, coordinating the services of the urban people, letting people experience an unprecedented and convenient way of living from a smart environment.

Finally, the collaborative development of hardware and software is required in the framework of intelligent environmental facilities, achieving unified standard and intelligent production in the development and manufacture of hardware, and using various modern technology to build intelligent environmental facilities. On the development and application of software, carrying out the combination of "platform" and variety, establishing a public and convenience service platform, bringing the urban people with convenient living conditions and windows to understand the information. Establishing database resources to support the services of cloud platforms and social public categories, and developing an convenience APP on the mobile side, and citizens can learn about the status of the city's intelligent public facilities and its environment on their mobile phones, Application development on the mobile side can also serve as a window for big data access, integrating fragmented information resources and giving people a more intuitive understanding or access to the required city data.

\section{Conclusion}

In the academic circles, there are fruitful theoretical research and practice in multifield and multidisciplinary centers on information communication, cloud computing, big data and artificial intelligence. These achievements support the wisdom of the earth, the smart city, the intellectual environmental facilities and even the intellectual life. The intelligent environmental facilities services and intelligent life support smart cities, solved numerous problems of the urban citizens and the environment, and there is a broad prospect for its future development. We'll see.

\section{Reference}

[1] Hollands R G. Will the real smart city please stand up? [J]. City. 2008, 12(3):303-320. 